\title{
The Superficial Inferior Epigastric Artery Flap and its Relevant Vascular Anatomy in Korean Women
}

\author{
Byung Jun Kim, Jun Ho Choi, Tae Hoon Kim, Ung Sik Jin, Kyung Won Minn, Hak Chang \\ Department of Plastic and Reconstructive Surgery, Seoul National University College of Medicine, Seoul, Korea
}

Background Lower abdominal soft tissue transfer is the standard procedure for breast reconstruction. However, abdominal wall weakness and herniation commonly occur postoperatively at the donor site. To reduce the morbidities of the donor site, the superficial inferior epigastric artery (SIEA) flap was introduced, but inconsistent anatomy of the SIEA has reduced its utility. In the present study, the anatomy of the superficial inferior epigastric vessels in Korean women was determined with regards to breast reconstructive surgery.

Methods The vascular anatomies of the SIEA and superficial inferior epigastric vein (SIEV) were evaluated on 32 breast cancer patients receiving free transverse rectus abdominis musculocutaneous flap reconstruction after mastectomy. The existence, pulsation, location, external diameter, and depth of the SIEA and SIEV were measured at the lower abdominal incision level.

Results SIEA and SIEV were present in 48/64 (75.00\%) and 63/64 (98.44\%) hemi-abdomens, respectively. Pulsation of the SIEA was found in $44 / 48$ (91.67\%) cases. The mean locations of SIEA and SIEV were $+5.79( \pm 12.87) \mathrm{mm}$, and $-8.14( \pm 15.24) \mathrm{mm}$ from the midpoint between the anterior superior iliac spine and symphysis pubis, respectively. The mean external diameters of SIEA and SIEV were $1.20( \pm 0.39) \mathrm{mm}$ and $1.37( \pm 0.33) \mathrm{mm}$, and they were found at a mean depth of $9.75( \pm 2.67) \mathrm{mm}$ and $8.33( \pm 2.65) \mathrm{mm}$, respectively.

Conclusions The SIEA was absent in $25 \%$ of Korean women and had a relatively small caliber. Therefore, careful preoperative assessment of the lower abdominal vasculature is required to achieve successful breast reconstruction using SIEA flaps.

Keywords Epigastric arteries / Regional anatomy / Koreans / Breast reconstruction
Correspondence: Hak Chang Department of Plastic and Reconstructive Surgery, Seoul National University College of Medicine, 101 Daehak-ro, Jongno-gu, Seoul 110-744, Korea

Tel: $+82-2-2072-3086$

Fax: +82-2-747-5130

E-mail: hchang@snu.ac.kr

Received: 13 Jun $2014 \bullet$ Revised: 22 Jul 2014 • Accepted: 18 Aug 2014

pISSN: 2234-6163 • elSSN: 2234-6171 • http://dx.doi.org/10.5999/aps.2014.41.6.702 • Arch Plast Surg 2014;41:702-708

This article was presented at the Korean Society of Plastic and Reconstructive Surgeons on November 1-3, 2013 in Seoul, Korea.

No potential conflict of interest relevant to this article was reported.

\section{INTRODUCTION}

The use of lower abdomen tissue for breast reconstruction was first described by Holmstrom in 1979 as a free flap, and was made popular by Hartrampf in 1982, who envisioned its utility as an abdominal island flap $[1,2]$. Upon advances in the microsurgical skills of surgeons, the abdomen tissue flap eventually evolved to the deep inferior epigastric perforator (DIEP) flap, which con- sists of skin and subcutaneous fat, and which has been demonstrated to decrease donor morbidity in terms of abdominal muscle impairment. Although the DIEP flap offers many advantages, intramuscular pedicle dissection is tedious, and it still requires excision of the abdominal fascia, which may cause prolonged hospital stays or donor site complications such as hernia $[3,4]$.

After the anatomy of the superficial inferior epigastric vessels was first studied in detail by Taylor and Daniel [5] in 1975, the 
utility of the superficial inferior epigastric artery (SIEA) flap for autologous tissue breast reconstruction started being reported in western literature in the early 1990s [6]. The minimal donor site morbidity in terms of abdominal wall weakness is owing to the fact that the abdominal wall muscle is intact during the SIEA flap procedure. However, there are also major disadvantages of the SIEA flap, including the inconsistent vascular pedicle anatomy and small diameter of the vascular pedicle for the free flap transfer of the whole abdominal tissue [7].

Previous studies about the SIEA anatomy have been mainly focused on Caucasian patients or human cadavers, and data on Asian patients are still lacking $[8,9]$. Thus, the purpose of the present study was to assess the anatomy of the superficial inferior epigastric vessels and to investigate the possibility and reliability of the SIEA free flap applied for reconstructive breast surgery in Korean female patients.

\section{METHODS}

Thirty-two Korean female patients who had undergone autologous tissue breast reconstructive surgery with free transverse rectus abdominis musculocutaneous (TRAM) flap immediately after mastectomy between April 2013 and October 2013 were enrolled in the present study.

Patients with underlying disease or general conditions that may have affected the vascular state, including hypertension, diabetes mellitus, atherosclerosis, obesity with severe risk of comorbidities (body mass index $[\mathrm{BMI}]>30 \mathrm{~kg} / \mathrm{m}^{2}$, according to World Health Organization guidelines for Asian populations [10]), history of smoking, or bleeding tendency, were excluded from the study. Moreover, patients with a history of Cesarean section, laparoscopic surgery, or liposuction were also excluded

\section{Fig. 1. The superficial inferior epigastric vessels}

The superficial inferior epigastric artery (lateral) and superficial inferior epigastric artery vein (medial) revealed at the lower abdominal incision level.

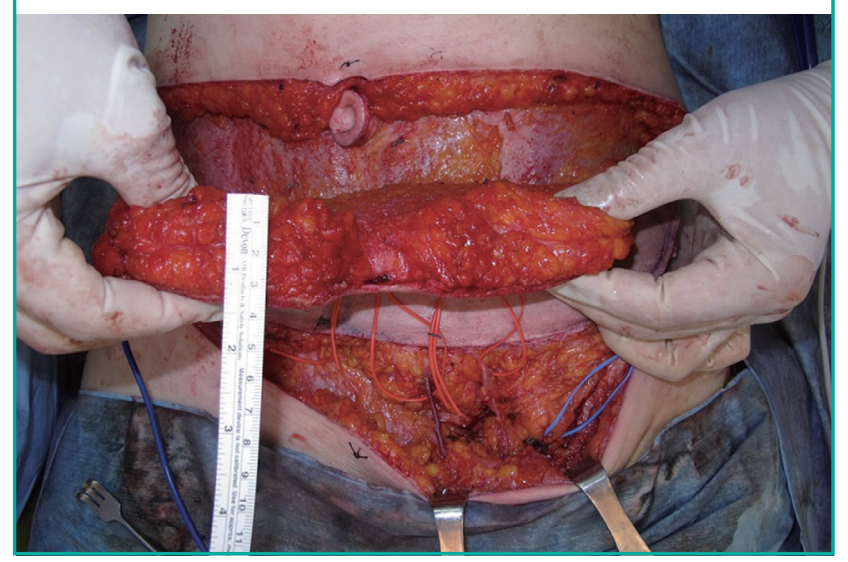

from this study to preclude the effect of these treatments on the vascular system of the lower abdomen. All patients were fully informed of the study and provided informed consent to participate. All procedures were performed under the approval of the institutional review board of our hospital (IRB number, 1303021-471) and in accordance with the Declaration of Helsinki.

All dissecting procedures were performed by one experienced plastic surgeon under $2.5 \times$ magnifications using a surgical telescope (Looks Corporation, Seoul, Korea). The patients were laid in the supine position, and the midline of the symphysis pubis (SP) and bilateral anterior superior iliac spine (ASIS) was marked on the surface of the patients' bodies. A conventional TRAM flap design was performed, independent of the location of the anatomical landmarks. The flap was a transversely elliptical shape superior to the inguinal ligament, including the umbilicus on midline at the upper incision line and the bilateral ASIS area. The vertical width was determined based on the possibility of primary closure of the donor tissue and requirements of the breast volume to be reconstructed. A Doppler probe was utilized to identify the major perforators of the DIEA, and its course. The lower abdominal incision was first made without infiltration of lidocaine or epinephrine in order to minimize any vasoactive effects. At the level of the lower abdominal incision of the TRAM flap, meticulous dissection was performed to discover the SIEA and superficial inferior epigastric vein (SIEV). An electrocoagulator was limitedly used to ensure hemostasis, and $4 \%$ lidocaine (Huons Corporation, Seoul, Korea) was applied around the vessels to avoid vessel spasm (Fig. 1).

At first, the existence of the SIEA and SIEV was documented along with the pulsation status of the SIEA. Next, the relative locations of the SIEA and SIEV were measured, and compared with the midpoint (M point) connecting the SP and ASIS. The

\section{Fig. 2. Gross anatomical landmarks for measurement}

The anterior superior iliac spine (ASIS), symphysis pubis (SP), and midpoint (M) are marked. From the midpoint, the locations of the vessels were identified. When the vessel is located lateral to the $M$ point,+ is expressed. When the vessel is located medial to the M point, - is expressed. SIEA, superficial inferior epigastric artery; SIEV, superficial inferior epigastric vein.

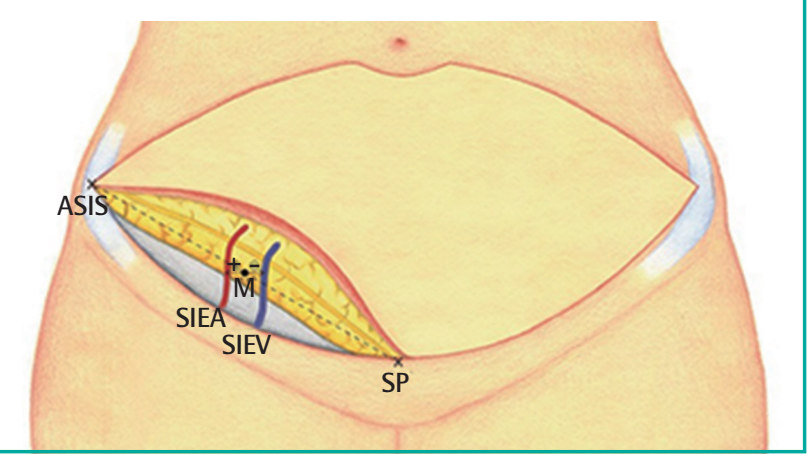


measurements were defined as positive when located lateral to the $M$ point, and negative when located medially. Finally, the external diameters and depth from the skin of the SIEA and SIEV were calculated using a Castroviejo caliper (Storz, Bausch \& Lomb Corporation, New York, NY, USA) (Fig. 2). The vessels were ligated after the measurements on the anatomy of SIEA and SIEV were completed, and followed by TRAM free flap elevation as per standard protocol. During the operation, the patients' systolic blood pressures were set to $100 \mathrm{~mm} \mathrm{Hg}$ on average, and no intraoperative anesthetic event was reported.

The distances of the SIEA and SIEV from each other and from the $M$ point were investigated. Unpaired t-test and Mann-Whitney test were used to determine the differences in how far the vessels were located from the midpoint, laterally or medially. A P-value $<0.05$ was considered statistically significant. Statistical analysis was performed using SPSS software ver. 20.0 (IBM Co., Armonk, NY, USA).

\section{RESULTS}

At the time of surgery, the mean age of the study patients was 43.46 years (range, $30-70$ years), and the mean BMI was 22.45 $\mathrm{kg} / \mathrm{m}^{2}$ (range, $17.97-28.93 \mathrm{~kg} / \mathrm{m}^{2}$ ).

The measurements obtained from 64 hemi-abdomen dissections revealed the presence of the SIEA and SIEV in 48 (75.00\%) and 63 cases (98.44\%), respectively. Of the total 48 SIEAs, pulsation was observed in 44 cases (91.67\%). At least one SIEA was absent in $12 / 32$ patients (37.50\%), and 4/32 patients showed bilateral absence of the SIEA (12.50\%). In 4 cases, the absence of pulsation was observed when the external diameter of the SIEA was less than $1 \mathrm{~mm}$. On the right side, SIEAs were present in $21 / 32$ cases (65.63\%), while 27 cases of SIEAs were found on the left side (84.38\%). However, the difference in the presence of the SIEA between the two sides was not statistically significant $(P=0.086)$. The SIEV was found in 31 cases out of 32 on the right side (96.88\%), and present in all cases on the left side (100\%).

On average, the SIEA was located $5.79( \pm 12.87) \mathrm{mm}$ lateral to the M point, whereas SIEV was located $8.14( \pm 15.24) \mathrm{mm}$ medial to the $M$ point. Based on the $M$ point, the tendency of lateral existence of the SIEA and tendency of medial existence of the SIEV were statistically significant $(\mathrm{P}<0.001)$. On the right side, the SIEA was relatively adjacent to the $M$ point $(3.78 \pm 10.96 \mathrm{~mm})$ compared with that on the left side $(7.35 \pm$ $14.18 \mathrm{~mm})$.

The average distance between the SIEA and SIEV was 17.64 $( \pm 12.81) \mathrm{mm} ; 23 / 48$ cases showed a distance of less than 15 $\mathrm{mm}, 18$ cases showed a distance between $15 \mathrm{~mm}$ and $30 \mathrm{~mm}$, and 7 cases showed a distance of more than $30 \mathrm{~mm}$.

The external diameters of the SIEA and SIEV were 1.20 $( \pm 0.39) \mathrm{mm}$ and $1.37( \pm 0.33) \mathrm{mm}$, respectively, and showed no statistical differences between the right and left sides. The mean caliber of the SIEA on the right side was $1.20( \pm 0.34)$, and that of the left side was $1.20( \pm 0.44)(P=0.967)$, while the SIEV on the right and left sides were $1.36( \pm 0.35)$ and 1.38 $( \pm 0.32)(P=0.872)$, respectively. Fifteen hemiabdomens (31.25\%) showed a relatively large caliber of the SIEA (larger than $1.5 \mathrm{~mm}$ ), while 18 (37.5\%) and 15 (31.25\%) hemiabdomens showed an SIEA caliber between $1.0 \mathrm{~mm}$ and $1.5 \mathrm{~mm}$, and less than $1.0 \mathrm{~mm}$, respectively.

The SIEA and SIEV were found above the Scarpa's fascia in all cases. Whether they were present or not, the SIEA and its two vena comitantes were more commonly identified in the deep subcutaneous tissue compared with the SIEV. The average depth of the SIEA from the skin was $9.75( \pm 2.67) \mathrm{mm}$, and that of SIEV was $8.33( \pm 2.65) \mathrm{mm}$. On the right and left sides, the SIEA was located at a mean depth of $9( \pm 2.36) \mathrm{mm}$ and 10.32 $( \pm 2.79) \mathrm{mm}$, respectively, whereas the SIEV was found at a depth of $8.28( \pm 2.62) \mathrm{mm}$ on the right side, and $8.38( \pm 2.72)$ $\mathrm{mm}$ on the left side. The depths of the SIEA showed no statistical differences between the right and left sides $(\mathrm{P}=0.123)$, and those of the SIEV revealed same results $(\mathrm{P}=0.901)($ Tables 1,2$)$.

\section{DISCUSSION}

The SIEA originates from the femoral artery inferior to the level

Table 1. Location, diameter, and depth of the superficial inferior epigastric vessels

\begin{tabular}{|c|c|c|c|c|c|c|}
\hline \multirow{2}{*}{ Variable } & \multicolumn{3}{|c|}{ SIEA } & \multicolumn{3}{|c|}{ SIEV } \\
\hline & Rt. SIEA (SD) & Lt. SIEA (SD) & Total (SD) & Rt. SIEV (SD) & Lt. SIEV (SD) & Total (SD) \\
\hline Location & $+3.78(10.96)$ & +7.35 (14.18) & $+5.79(12.87)$ & $-8.42(16.37)$ & $-7.88(14.33)$ & $-8.14(15.24)$ \\
\hline Diameter & $1.20(0.34)$ & $1.20(0.44)$ & $1.20(0.39)$ & $1.36(0.35)$ & 1.39 (0.32) & $1.37(0.33)$ \\
\hline Depth & $9.00(2.36)$ & $10.32(2.79)$ & $9.75(2.67)$ & 8.28 (2.62) & $8.38(2.72)$ & 8.33 (2.65) \\
\hline
\end{tabular}


of the inguinal ligament, and runs toward the superolateral side of the lower abdomen. It is located in the subcutaneous tissue above Scarpa's fascia as it ascends beyond the inguinal ligament. The branches of the SIEA communicate with the intercostal arteries and circumflex iliac arteries laterally, and with the deep in-

Table 2. Anatomical value of the SIEA and representative parameters that support the merit of SIEA flaps for breast reconstruction in 64 hemi-abdomens

\begin{tabular}{lcc|}
\hline Parameters & Number & Percentage (\%) \\
\hline SIEA presence & $48 / 64$ & - \\
Diameter > 1.5 mm (mean: $1.2 \mathrm{~mm}$ ) & $15 / 48$ & 31.25 \\
Pulsation & $44 / 48$ & 91.67 \\
SIEA lateral to M point (mean: $5.79 \mathrm{~mm}$ ) & & \\
$\quad<5 \mathrm{~mm}$ & $26 / 48$ & 54.17 \\
$\quad 5-10 \mathrm{~mm}$ & $7 / 48$ & 14.58 \\
$\quad>10 \mathrm{~mm}$ & $15 / 48$ & 31.25 \\
SIEA-SIEV distance (mean: $17.64 \mathrm{~mm}$ ) & & \\
$\quad<15 \mathrm{~mm}$ & $23 / 48$ & 47.92 \\
$\quad 15-30 \mathrm{~mm}$ & $18 / 48$ & 37.50 \\
$\quad>30 \mathrm{~mm}$ & $7 / 48$ & 14.58 \\
Diameter >1.5 mm with pulsation, & & \\
$\quad<10 \mathrm{~mm}$ lateral to the M point, & $7 / 48$ & 14.58 \\
$\quad$ and SIEA-SIEV < 30 mm & & \\
\hline Overall presence of SIEA was 75\% (48/64). & \\
SIEA, superficial inferior epigastric artery; SIEV, superficial inferior epigastric \\
vein.
\end{tabular}

ferior epigastric system medially $[2,11,12]$. The dominant blood circulation to the lower abdomen originates from the musculocutaneous perforators supplied by the deep inferior epigastric system, and the superficial inferior epigastric system based on the subdermal vascular network has a mutual relationship with the deep inferior epigastric system [12].

To reduce donor site morbidities, the lower abdominal flaps used for reconstructive breast surgery have been evolved from muscle sparing TRAM or DIEP to SIEA flaps [7]. The SIEA flap does not sacrifice the fascia of the rectus abdominis muscle, and allows the operation time to be reduced due to its relatively easy pedicle dissection. Since 1991, when Grotting [13] first introduced the free SIEA flap for reconstructive breast surgery, it has been the first choice for breast reconstruction by many surgeons $[14,15]$.

Despite of the definite advantages of the SIEA flap, its clinical use is somewhat limited because of the anatomical variability of the SIEA. Taylor and Daniel [5] first evaluated the anatomy of the SIEA in cadavers, and since then, numerous studies have been conducted on the anatomy of the SIEA and the clinical usability of the SIEA flap. These studies, which consisted of clinical operative dissection, clinical operative imaging or perfusion, cadaveric dissection, and cadaveric imaging studies, reported the presence of SIEA in between $30 \%-100 \%$ of cases; and the

Table 3. Literature review

\begin{tabular}{|c|c|c|c|c|c|c|c|c|c|c|c|}
\hline Reference (year) & Country & $\mathrm{N}$ & Type & Site & $\begin{array}{c}\text { P of } A \\
(\%)\end{array}$ & $\begin{array}{c}\text { P of V } \\
(\%)\end{array}$ & $\begin{array}{c}\text { Pulsation } \\
(\%)\end{array}$ & $\begin{array}{c}\text { D of } A \\
(\mathrm{~mm})\end{array}$ & $\begin{array}{l}\text { D of } V \\
(\mathrm{~mm})\end{array}$ & $\begin{array}{l}\text { L of } A \\
(\mathrm{~mm})\end{array}$ & $\begin{array}{l}\text { L of V } \\
(\mathrm{mm})\end{array}$ \\
\hline Present study (2014) & Korea & 64 & COD & LAl & $48 / 64(75)$ & 63/64 (98) & $44 / 48$ (91.67) & 1.2 & 1.37 & +5.79 & -8.14 \\
\hline Herrera et al. (2010) & USA & 64 & COD & LAl & $51 / 64(80)$ & 64/64 (100) & NR & NR & NR & NR & NR \\
\hline Gusenoff et al. (2008) [21] & USA & 64 & COD & LAl & $52 / 64(81)$ & 63/64 (98) & NR & 1.7 & 2.9 & $N R$ & $N R$ \\
\hline Spiegel et al. (2007) [1] & USA & 278 & COD & LAl & $160 / 278(58)$ & NR & NR & NR & NR & NR & NR \\
\hline Selber et al. (2008) [3] & USA & 638 & COD & LAl & NR & $N R$ & NR & $N R$ & $N R$ & $N R$ & NR \\
\hline Vega et al. (2006) [24] & USA & 62 & COD & LAl & NR & NR & NR & NR & NR & NR & NR \\
\hline Chevray et al. (2004) [14] & USA & 47 & COD & LAl & $23 / 47(49)$ & NR & NR & $N R$ & NR & NR & NR \\
\hline Dorafshar et al. (2010) [6] & USA & 143 & COD & $\|$ & NR & NR & NR & 0.96 & 2.27 & NR & NR \\
\hline Ulusal et al. (2006) [8] & Taiwan & 44 & COD & Or & $23 / 44(52)$ & NR & NR & 2 & 2.7 & NR & NR \\
\hline Arnez et al. (1999)[15] & Slovenia & 20 & COD & Or & $12 / 20(60)$ & NR & NR & NR & $N R$ & NR & NR \\
\hline Stern et al. (1992) [16] & USA & 31 & COD & Or & NR & NR & NR & NR & NR & NR & NR \\
\hline Holm et al. (2007) [25] & Germany & 84 & CIP & LAl & NR & NR & NR & NR & NR & NR & NR \\
\hline Rozen et al. (2009) [20] & Australia & 500 & CIP & NR & $468 / 500(94)$ & $500 / 500(100)$ & NR & 0.6 & $N R$ & NR & NR \\
\hline Fathi et al. (2008) [22] & Iran & 40 & $\mathrm{CD}$ & $\| \mathrm{L}$ & $38 / 40$ (95) & $40 / 40(100)$ & NR & 1.45 & 2.14 & $\begin{array}{l}\text { Within } \pm 10 \\
(33 / 38,87 \%)\end{array}$ & $\begin{array}{l}\text { Within } \pm 10 \\
(35 / 40,88 \%\end{array}$ \\
\hline Rizzuto et al. (2004) [19] & USA & 100 & $\mathrm{CD}$ & $\| \mathrm{L}$ & $72 / 100(72)$ & NR & NR & 1.6 & NR & NR & NR \\
\hline Reardon et al. (2004) [2] & Ireland & 22 & $\mathrm{CD}$ & Or & 20/22 (91) & $21 / 22(95)$ & NR & 1.9 & 2.1 & $\begin{array}{l}\text { Within } \pm 10 \\
(15 / 20,75 \%)\end{array}$ & NR \\
\hline Taylor et al. (1975) [5] & Australia & 100 & $C D$ & Or & $65 / 100(65)$ & NR & NR & 1.4 & NR & NR & NR \\
\hline Schaverien et al. (2008) [23] & USA & 24 & $\mathrm{CD}$ & NR & $8 / 24(33)$ & NR & NR & $N R$ & NR & NR & $N R$ \\
\hline
\end{tabular}

When the vessel is located lateral to the $\mathrm{M}$ point, + is expressed. When the vessel is located medial to the $\mathrm{M}$ point, - is expressed.

$\mathrm{N}$, the number of hemi-abdominal specimens; Type, the study modality type, and site indicates the level of measurement; $P$ of $A$, presence of the SIEA; $P$ of $V$, presence of the SIEV; $D$ of $A$, diameter of the SIEA; $D$ of $V$, diameter of the SIEV; $L$ of $A$, location of the SIEA away from the $M$ point; $L$ of $V$, location of the SIEV away from the M point; COD, clinical operative dissection; LAl, lower abdominal incision; NR, not recorded; IL, inguinal ligament; Or, origin; CIP, clinical imaging or perfusion study; CD, cadaveric dissection; SIEA, superficial inferior epigastric artery; SIEV, superficial inferior epigastric vein. 
average diameter of the SIEA was found to differ according to the study type and level of measurement, ranging between 0.6 to $2.9 \mathrm{~mm}$ (Table 3) [16-19].

According to Rozen et al. [20], cadaver studies are limited due to the post-mortem changes in vascular anatomy, and the fact that the physiologic features of vessel cannot be assessed, although complete exposure and meticulous dissection is possible. Imaging studies have several advantages, such as non-invasiveness, large cohorts, and being able to evaluate the dynamic perfusion to the lower abdominal tissue [17]. However, accurate measurements of the vessel diameter or the presence of SIEA pulsation is difficult, and the complicated vasculature of the lower abdomen can interfere with these studies. On the other hand, clinical dissection studies have revealed substantial physiologic vascular anatomy, and have provided direct information when determining the optimal type of abdominal flap. These studies also have limitations in terms of incomplete exposure of the vascular anatomy, which is confined to the surgical field, owing to ethical problems associated with the prolonged operation time $[1,6]$. Furthermore, the intraoperative decision of a pedicle between the SIEA and DIEA should be made according to the status of the SIEA at lower abdominal incision level, not according to the external diameter of the SIEA at the level of origin $[19,21,22]$.

Spiegel and Khan [1] created an intraoperative algorithm for breast reconstruction, and recommended using the SIEA flap only if the diameter of the SIEA was $>1.5 \mathrm{~mm}$ at the lower abdominal incision level, as SIEAs with a diameter of $<1.5 \mathrm{~mm}$ showed higher rates of fat necrosis and partial flap loss due to arterial thrombosis. They also found higher incidences of arterial thrombosis at the point of kinking as the SIEA entered the flap during re-exploration. Of note, the pedicle enters into the sub- cutaneous border of SIEA flaps, whereas it enters into the inferior surface of TRAM and DIEP flaps [23]. The kinking can result in narrowing of the pedicle, and increase the risk of vascular compromise; therefore, the diameter at the entry point into the flap is more important than the diameter at the origin (Fig. 3).

We believe that the present study is of substantial clinical importance, as, to our knowledge, this is the first clinical study about the anatomy of the SIEA in Asian females. In Taiwan, Ulusal et al. [8] reported that the mean diameters of the SIEA and SIEV were $2.0 \mathrm{~mm}$ and $2.7 \mathrm{~mm}$, respectively. While their study was also a clinical study, the values were selectively obtained when the SIEA flaps were chosen for breast reconstruction at the level of origin. In the present study, we examined the diameters of the SIEA and SIEV at the level of the lower abdominal incision, which may provide more helpful information in deciding the optimal flap type [8].

There are four major factors to take into account when the SIEA flap is favored for reconstructive breast surgery. First, the external caliber of the SIEA should exceed $1.5 \mathrm{~mm}$ at the level of the lower margin of the flap $[3,6,15,17,20,22,24]$. Second, the pulsation of the SIEA should be visible to the naked eye $[1,6,14]$. Third, a more medial position of the SIEA from the midline should be guaranteed, because the SIEA supplies a lesser territory of the flap across the midline $[2,17,20,25]$. Forth, proximity of the SIEA with the SIEV is an essential factor to allow the use of both vessels as the same recipient vascular pedicle for microanastomosis $[2,17,25]$. The data of the present study were analyzed according to these criteria. We found that only $14.58 \%$ (7/48) of the hemiabdomens met all criteria, including a SIEA larger than $1.5 \mathrm{~mm}$ in diameter with pulsation, a relatively medial position away from the $\mathrm{M}$ point, and an approximate distance to the SIEV of less than $30 \mathrm{~mm}$ (Table 2).

Fig. 3. Anatomy of vascular pedicles entering the flaps

Comparison of the vascular pedicles between the transverse rectus abdominis musculocutaneous flap (A) and superficial inferior epigastric artery flap (B). In the superficial inferior epigastric artery flap, vascular pedicles which enter the flap can be kinked (graphically described as ${ }^{*}$ on the Fig. B), therefore the blood flow at the kinking point becomes slow, and the risk of vascular compromise increases.
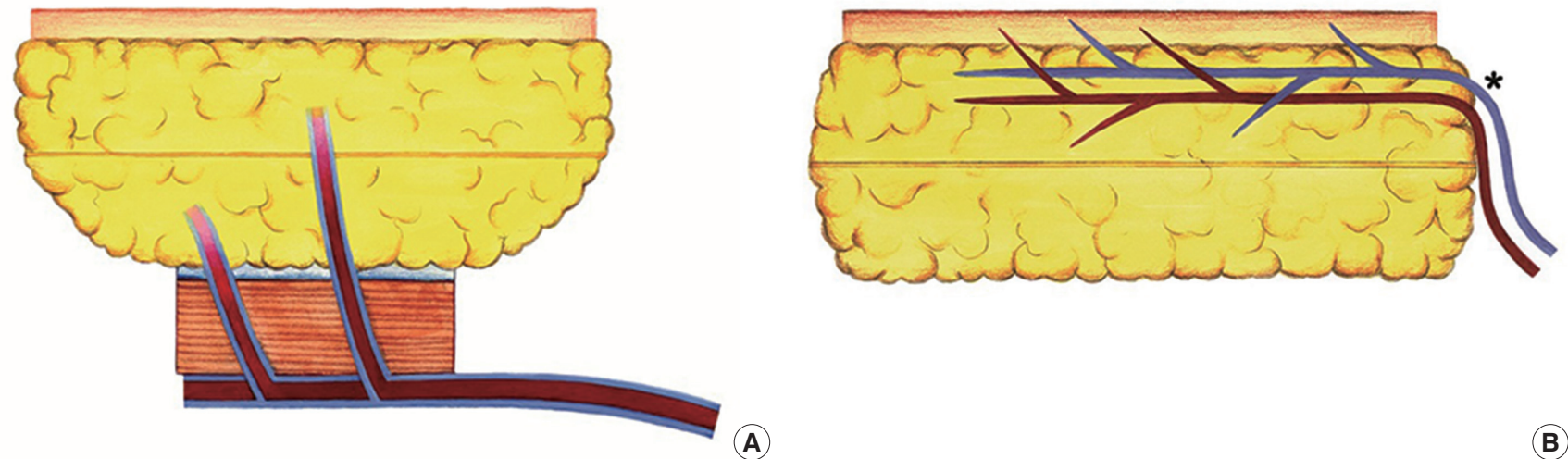
The relatively low BMI and small volume of abdominal tissue of Korean women may reduce the pressure burden of the flap on the vascular pedicle. Moreover, Korean women also have relatively small breasts; and therefore, a SIEA flap may represent a good option when whole abdominal tissue is not required. The relative small caliber of the SIEA is compatible with the perforator of the internal mammary artery [12], and preoperative imaging and Doppler sonographic tracing on the inferior epigastric vessels of both the deep and superficial systems will provide additional clues in determining the optimal type of flap.

Based on the literature review, we considered that a SIEA larger than $1.5 \mathrm{~mm}$ in diameter is reliable as a vascular pedicle. However, most of studies represent the value of western populations, and the value may differ from that of Asian populations. Therefore, further studies are needed to set new safety criteria for the Asian patients.

In conclusion, the vascular anatomy favoring SIEA flaps for breast reconstruction was found in only $14.58 \%$ of cases (7/48). Therefore, careful preoperative assessment on the lower abdominal vasculature and strict indication for SIEA flaps are required to achieve successful breast reconstruction using SIEA flaps in Asian patients. Large-scale data of the SIEA and clinical results of breast reconstruction using SIEA flaps are warranted in future studies.

\section{REFERENCES}

1. Spiegel AJ, Khan FN. An Intraoperative algorithm for use of the SIEA flap for breast reconstruction. Plast Reconstr Surg 2007;120:1450-9.

2. Reardon CM, O'Ceallaigh S, O'Sullivan ST. An anatomical study of the superficial inferior epigastric vessels in humans. Br J Plast Surg 2004;57:515-9.

3. Selber JC, Samra F, Bristol M, et al. A head-to-head comparison between the muscle-sparing free TRAM and the SIEA flaps: is the rate of flap loss worth the gain in abdominal wall function? Plast Reconstr Surg 2008;122:348-55.

4. Zenn MR. Insetting of the superficial inferior epigastric artery flap in breast reconstruction. Plast Reconstr Surg 2006; 117:1407-11.

5. Taylor GI, Daniel RK. The anatomy of several free flap donor sites. Plast Reconstr Surg 1975;56:243-53.

6. Dorafshar AH, Januszyk M, Song DH. Anatomical and technical tips for use of the superficial inferior epigastric artery (SIEA) flap in breast reconstructive surgery. J Reconstr Microsurg 2010;26:381-9.

7. Hsieh F, Kumiponjera D, Malata CM. An algorithmic approach to abdominal flap breast reconstruction in patients with pre-existing scars--results from a single surgeon's experience. J Plast Reconstr Aesthet Surg 2009;62:1650-60.

8. Ulusal BG, Cheng MH, Wei FC, et al. Breast reconstruction using the entire transverse abdominal adipocutaneous flap based on unilateral superficial or deep inferior epigastric vessels. Plast Reconstr Surg 2006;117:1395-403.

9. Imanishi N, Nakajima H, Minabe T, et al. Anatomical relationship between arteries and veins in the paraumbilical region. Br J Plast Surg 2003;56:552-6.

10. World Health Organization Western Pacific Region, International Association for the Study of Obesity, International Obesity Task Force. Redefining obesity and its treatment [Internet]. Geneva: World Health Organization; 2000 [cited 2014 Aug 22]. Available from: http://www.who.int/nutrition/publications/obesity/09577082_1_1/en/.

11. Hester TR Jr, Nahai F, Beegle PE, et al. Blood supply of the abdomen revisited, with emphasis on the superficial inferior epigastric artery. Plast Reconstr Surg 1984;74:657-70.

12. Granzow JW, Levine JL, Chiu ES, et al. Breast reconstruction using perforator flaps. J Surg Oncol 2006;94:441-54.

13. Grotting JC. The free abdominoplasty flap for immediate breast reconstruction. Ann Plast Surg 1991;27:351-4.

14. Chevray PM. Breast reconstruction with superficial inferior epigastric artery flaps: a prospective comparison with TRAM and DIEP flaps. Plast Reconstr Surg 2004;114:1077-83.

15. Arnez ZM, Khan U, Pogorelec D, et al. Breast reconstruction using the free superficial inferior epigastric artery (SIEA) flap. Br J Plast Surg 1999;52:276-9.

16. Stern HS, Nahai F. The versatile superficial inferior epigastric artery free flap. Br J Plast Surg 1992;45:270-4.

17. Holm C, Mayr M, Hofter E, et al. Interindividual variability of the SIEA Angiosome: effects on operative strategies in breast reconstruction. Plast Reconstr Surg 2008;122:161220.

18. Woodworth BA, Gillespie MB, Day T, et al. Muscle-sparing abdominal free flaps in head and neck reconstruction. Head Neck 2006;28:802-7.

19. Rizzuto RP, Allen RJ. Reconstruction of a partial mastectomy defect with the superficial inferior epigastric artery (SIEA) flap.J Reconstr Microsurg 2004;20:441-5.

20. Rozen WM, Chubb D, Grinsell D, et al. The variability of the Superficial Inferior Epigastric Artery (SIEA) and its angiosome: a clinical anatomical study. Microsurgery 2010; 30:386-91.

21. Gusenoff JA, Coon D, De La Cruz C, et al. Superficial inferior epigastric vessels in the massive weight loss population: implications for breast reconstruction. Plast Reconstr Surg 2008;122:1621-6. 
22. Fathi M, Hatamipour E, Fathi HR, et al. The anatomy of superficial inferior epigastric artery flap. Acta Cir Bras 2008;23: 429-34.

23. Schaverien M, Saint-Cyr M, Arbique G, et al. Arterial and venous anatomies of the deep inferior epigastric perforator and superficial inferior epigastric artery flaps. Plast Reconstr Surg 2008;121:1909-19.
24. Vega SJ, Bossert RP, Serletti JM. Improving outcomes in bilateral breast reconstruction using autogenous tissue. Ann Plast Surg 2006;56:487-90.

25. Holm C, Mayr M, Hofter E, et al. The versatility of the SIEA flap: a clinical assessment of the vascular territory of the superficial epigastric inferior artery. J Plast Reconstr Aesthet Surg 2007;60:946-51. 